\title{
Ectomycorrhizal fungi associated with Arctostaphylos uva-ursi in Scotland: Exploring the biogeography of undiscovered fungal communities
}

\author{
EMILY HESLING and ANDY F.S. TAYLOR
}

\begin{abstract}
HESLING, E \& TAYLOR, A.F.S. 2013: Ectomycorrhizal fungi associated with Arctostaphylos uva-ursi in Scotland: Exploring the biogeography of undiscovered fungal communities. - Karstenia 53: 00-00. HELSINKI. ISSN 0453-3402.

In the Scottish alpine environment there is a suite of ecologically significant plant species that are obligately associated with ectomycorrhizal (ECM) fungi. These plant species are in decline, and at present little is known about the potentially diverse communities of mycorrhizal fungi associated with them. This study sets out to provide a baseline description of the ECM community associated with Arctostaphylos uva-ursi over seven sub-alpine/alpine sites in the Scottish highlands. Traditional identification and Sanger sequencing of collected fruit bodies, coupled with next-generation sequencing of host plant root material were used to detect and identify ECM taxa. The ECM community was diverse, with 84 taxa identified to genus level. Only 29 of these are species previously recorded in Scotland. Eight species represent new records for Scotland and the remaining 47 taxa have not yet been identified to species level and are likely to include many currently undescribed species. $39 \%$ of species belonged to the genus Cortinarius, whilst Sebacina, Inocybe, Tomentella, Leccinum and Russula were also well represented. Community composition was similar to arctic-alpine ECM communities described elsewhere, but is unique within Scotland. The community was particularly dominated by Suillus variegatus, a species considered to be a specialist associate of Pinus spp. Almost one-fifth of species detected were 'specialist' associates of tree species, highlighting the potential capability of $A$. uva-ursi ECM communities to facilitate upland woodland regeneration in Scotland. This research should draw awareness to a highly diverse, but poorly recorded community, restricted to a rapidly declining habitat in Scotland.
\end{abstract}

Key words: Ectomycorrhiza, Arctostaphylos uva-ursi, alpine, low-alpine, inoculum, afforestation, Scotland, arctic-alpine mycology

Emily Hesling and Andy Taylor, James Hutton Institute, Macaulay Drive, Aberdeen, AB158QH, UK; emails: emilyhesling@gmail.com; andy.taylor@hutton.ac.uk

\section{Introduction}

Arctic-alpine habitats are experiencing rapid change under the influences of climate change, elevated nitrogen deposition and land use both in Scotland and globally (Britton et al. 2009, Lenoir et al. 2008). They are inhabited by a group of fungi that perform a critical role supplying a suite of obligately dependent shrubs with nutri- ents required for survival and growth in these typically nutrient poor and climatically harsh habitats. However, mycological records are scarce within these habitats in Scotland, with no systematic procedures in place to establish data on fungal community composition or species biogeography. Historical recording of ectomycorrhizal (ECM) fungi in the sub-alpine and alpine zones of Scotland has been largely limited to the 
fungal associates of Salix repens and Salix herbacea (Hollingsworth \& Iason 2005, Milne et al. 2006, Watling 2005). There are currently either very few or no records of fungi associated with other hosts such as Arctostaphylos spp., Betula nana, Dryas octopetala, Polygonum viviparum or other Salix shrub species. Watling (2002) discussed the association of several ECM macromycete species with Arctostaphylos uva-ursi in Scotland, however only 18 species of ECM fungi have currently been recorded with this host in the Fungal Records Database of the British Isles (FRDBI 2012). To date there has been no systematic survey of this habitat. This study sets out to establish baseline data to describe the ECM community associating with $A$. uva-ursi in subalpine and alpine habitats in Scotland.

Arctostaphylos uva-ursi is a procumbent ericaceous shrub which occurs as a dominant component of coastal heath on the north and northwest coasts of Scotland; inland within Pinus sylvestris forests as an understorey component; through the tree-line and beyond in ericaceous heathland; and up into the low-alpine zone to around $850 \mathrm{~m}$ a.s.l. in alpine heaths of the central Cairngorm mountain range. The national range of $A$. uva-ursi appears to have remained stable over the last century (Preston et al. 2002), but populations have been shown to be in dramatic local decline in some areas (Britton et al. 2009).

A study on a glacier forefront in the Austrian Alps recorded 99 ECM taxa in association with A. uva-ursi (Krpata et al. 2007) including species known to be specific to other hosts. This generalist associative trait of $A$. uva-ursi is credited for its apparent ability to facilitate local tree regeneration, potentially by providing fungal inoculum for seedlings. In Scotland, A. uva-ursi heaths currently inhabit the altitudes at which a Pinus sylvestris - Betula pubescens tree-line would exist at the base of the low-alpine zone were it not for deforestation over the past 500 years (Horsfield \& Thompson 1996). Regeneration of upland native woodland is a conservation priority in Scotland (Forestry Commission 2009), therefore understanding the availability of ECM inoculum suitable for these tree species would be of benefit. This study uses traditional fruit-body collection and identification, coupled with next-generation sequencing of root associated fungi to provide a species list of ECM fungi that occur in association with A.uva-ursi. Below ground sequence data also provides an approximate measure of relative abundance for taxa detected. This article is part of the proceedings of the $9^{\text {th }}$ International Symposium of Arctic and Alpine Mycology (ISAM) held at Kevo Subarctic Research Station in Inari Lapland, Finland, 26.08.-01.09.2012.

\section{Material and methods}

Study sites: Seven sites were selected across mainland Scotland, incorporating both the major population centres and geographical extremes of the host $A$. uva-ursi's known range (Fig. 1). A single visit was made to each site between August and October 2010, with one additional visit to sites $\mathrm{A}$ and $\mathrm{C}$, and four additional visits to site B (including one visit in October 2009) for additional fruit body collection. At each site the highest altitudinal patch of the host found was selected for sampling, which in each area was above the extant tree line. Sampling was then conducted within a $100 \times 100 \mathrm{~m}$ plot in this area.

Fruit body collection and analysis: All fruit bodies seen within the site area were collected, up to a limit of three collections per discernible species. Collections were photographed when possible, transported to the lab within 24 hours and then described, dried and stored. DNA was extracted from a small section of the lamellae, pores or spore mass and then amplified using CTAB extraction and PCR protocols as in Irmark et al. (2012). Amplicons were then purified and Sanger sequenced by Macrogen Europe (Amstelveen, Netherlands). Sequences were checked for quality, and searched against the UNITE (Abarenkov et al. 2010) and INSD (GenBank, EMBL, DDBJ) databases using BLASTn (Altschul 1990) through the UNITE portal (http://unite.ut.ee/analysis.php).

Below ground sampling: In each site area ten plants were selected, from which fine roots were traced, and three samples spaced around the plant were collected each containing a minimum of 100 mycorrhizal root tips. The root samples from a site were bulked to give a single sample per site, cleaned to remove all visible soil debris and woody root sections, and then screened under $\times 3.15$ magnification to check that only $A$. uva-ursi roots were included. The number of live root tips were counted per sample. Samples were freeze-dried, then milled into a fine powder.

Below ground molecular analysis: Three replicate DNA extractions were performed for each sample using DNeasy Plant Minikit (QIAGEN, Hilden, Germany) using $20 \mathrm{mg}$ of milled root per reaction, then combined to give a single extract per sample. Quantitative PCR was performed to determine the optimum PCR template dilution and number of PCR cycles per sample extract, requiring dilutions in the range of $1 / 200$ to $1 / 10000$, with 25 or 27 PCR cycles. The ITS 2 region was amplified in 5 replicate PCR reactions for each sample to provide sufficient DNA for sequencing. PCR was conducted on a 2720 
Thermal Cycler (Life Technologies, Carlsbad, CA,USA) in $50 \mu \mathrm{l}$ reactions: $25 \mu \mathrm{l}$ of diluted template; $200 \mu \mathrm{M}$ of each nucleotide; $2.75 \mathrm{mM} \mathrm{MgCl2;} 200 \mathrm{nM}$ ITS7A primer (Ihrmark et al. 2012); 200 nM ITS 4 primer with a 3' 8bp tag distinct by at least $2 \mathrm{bp}$ for each sample; and 0.025 U/ $\mu$ l polymerase (DreamTaq Green, Thermo Scientific, Waltham, MA, USA) in buffer. Cycling parameters were: $94^{\circ} \mathrm{C}$ for $5 \mathrm{~min}$ then 25 to 27 cycles at $94^{\circ} \mathrm{C}$ for $30 \mathrm{~s}$; $57^{\circ} \mathrm{C}$ for $30 \mathrm{~s} ; 72^{\circ} \mathrm{C}$ for $30 \mathrm{~s}$; with a final extension of $72^{\circ} \mathrm{C}$ for $7 \mathrm{~min}$. PCR products were purified using the AMPure 96 kit (Beckman Coulter, Brea, CA). Amplicon DNA concentrations were established using a Qubit 1.0 fluorometer (Invitrogen, Paisley, UK). They were then mixed in equal molar proportion into a combined sample, which was further purified using a GeneJET PCR Purification kit (Thermo Scientific, Waltham, MA, USA), freeze-dried and then subjected to 454-sequencing after addition of sequencing adaptors by ligation. Adaptor ligation and sequencing was performed by LGC Genomics GmbH (Berlin, Germany) on a GL FLX Titanium system (Roche, Basel, Switzerland).

Below ground data analysis: Within the SCATA pipeline (scata.mykopat.slu.se) sequences were filtered discarding strands with an average quality score below 20 or below 10 at any position, shorter than $100 \mathrm{bp}$ or missing 5' or 3' primers and tags. Sequences were then were trimmed of ITS4 and ITS7A primers and clustered with a stringency of $98.5 \%$ similarity. Clusters were searched against the UNITE and INSD databases and fruit body sequences generated by this study using BLASTn. Taxa pertaining to non-ectomycorrhizal genera were discarded (Rinaldi et al. 2008, Tedersoo et al. 2010a). NeighbourJoining phylogenies were constructed using the ITS2 sequences within genera and subgenera for all fruit-body and root associated ECM sequences to optimise grouping of records into putative taxa. Funga Nordica (Knudsen \& Vesterholt, 2012) and Mycobank (Crous et al. 2004) were used as authoritative references on extant species. Voucher specimens are kept in the personal collection of AFS Taylor held at The James Hutton Institute, Aberdeen, Scotland.

\section{Results}

Across four of the seven sites surveyed (A-D), 128 fruit body collections were made, identified as 40 ectomycorrhizal species (Table 1). No fruit bodies were observed during visits to the remaining three sites. Fifty-seven thousand root tips were analysed over the seven sites, from which thirty-five thousand ITS2 sequences passed quality control. These were assigned to ectomycorrhizal operational taxonomic units clustered at the $98.5 \%$ similarity level, considered hencewith as 'taxa'. Over the seven sites studied, 12 species collected as fruit bodies were also detected molecularly in association with the roots of A. uva-ursi. A further 44 taxa were detected only on roots, giving a total of 84 taxa recorded and identified to genus level. Thirty-seven taxa were assignable to described species, eight of which have not previously been recorded in Scotland. Eight species were also putatively identified to species level, but more data is required for confirmation. No conclusive match was found for the remaining 39 taxa to any ITS sequence in public databases identified to species level.

The 84 taxa recorded belong to 20 genera. These were dominated by the genus Cortinarius comprising 33 taxa (39\%), whilst Sebacina, Inocybe, Tomentella, Leccinum and Russula were also specious groups. The ECM community was particularly dominated by Suillus variegatus, detected on roots at all seven sites, and comprising more than $10 \%$ of root associated sequence reads at five of these. Other dominant species included Suillus luteus, Leccinum cf. vulpinum coll. spp. $1 \& 2$, Cortinarius elatior s. Bendiksen, Cortinarius Sect. Dermocybe sp. 2, Tomentellopsis submollis, and Thelephora terrestris. A small number of species are likely to be alpine specialist species, for example Russula nana and C. aff. pauperculus. Notably $19 \%$ of species detected are considered to be host specific to Pinus: Cortinarius bayeri, C. carabus, C. fusisporus, C. melitosarx, Inocybe sambucina, Russula sardonia, Suillus luteus, S. variegatus, Tricholoma focale. Host specific to Betula are: Leccinum cf. niveum and L. variicolor, and to Picea: C. albovariegatus ss. (Velen.) Melot, C. floccopus, $C$. fulvescens, $C$. vibratilis and Lactarius sphagneti. Several of these species were particularly prevalent within the below ground communities. All other identified species are generalists with lower host specificity, documented as associating with a number of tree or shrub species (Knudsen \& Vesterholt 2012).

Below ground richness in taxa was relatively comparable across sites ( $\mathrm{n}=16$ to 23 ), and is low considering the sensitivity of next-generation sequencing and the high species richness of fruit bodies collected at the highly sampled site B. This is likely to reflect the sampling limitation of ten host plants per site, which in hindsight appears insufficient to deal with the spatial heterogeneity of ECM genets across a site. The number of root tips sequenced for each site did not correlate with taxa richness. 


\section{Discussion}

Only $36 \%$ percent of species detected in this study have been identified as species previously recorded in the United Kingdom. The high proportion of previously unrecorded taxa includes several fruit body collections intended for novel species description, and at least eight new species records for Scotland. It is highly unusual in modern times for such a high proportion of previously unrecorded species be found within a habitat of the UK, where relative to many other countries there is a long and detailed history of fungal species recording. This reflects the comparatively low level of recording within this habitat in the UK, but is also due to the application of molecular techniques unveiling taxa within cryptic groups such as the Cortinarius subgenus Telamonia. Additionally next-generation sequencing has identified species potentially missed by fruit body collection and root tip morphotyping techniques

The ECM community detected is very similar in structure to that found with $A$. uva-ursi in the Austrian Alps by Krpata et al. (2007), with a large proportion of species of generalist host association and habitat preference, a small proportion of alpine specific species, and a prevalence of the genera Cortinarius, Sebacina, Inocybe, Russula, Suillus and Tomentella. The dominance of Cortinarius in terms of the species richness of the ECM community is a common trait in arctic and alpine communities (Jumpponen et al. 2002, Kernaghan \& Currah 1998, Kernaghan \& Harper 2001, Krpata et al. 2007, Nara 2006). Adaptive alpine specialisation amongst species may be an explanation for the high number of unidentified species and those previously unrecorded in the UK.

A considerable proportion of species detected are considered host specific to Pinus, Betula or Picea. Sites were all well above the existing treeline, and tree species are likely to have been absent for at least several hundred years. Several of these species, notably Suillus and Leccinum species, were particularly dominant below ground strongly suggesting that these fungal species are permanent associates of $A$. uva-ursi within the alpine habitat. This is in accordance with the observations of Krpata el al. (2007), Molina \& Trappe (1982) and Zak (1976) who found that $A$. uva-ursi is a generalist host capable of accepting 'specialist' fungi. Interestingly Picea spp. are not native to the UK, so Picea specialist fungi have either colonised A. uva-ursi in the last century from stands of commercially grown introduced Picea, or have been resident with A. uva-ursi since arctic and alpine vegetation recolonised Scotland during deglaciation around 9700 y BP (Birks \& Mathewes 1978).

Very few natural altitudinal tree lines exist in Scotland, since the uplands have largely been deforested. However, regeneration of the upland woodland including low alpine scrub has become a conservation activity within recent decades (Forestry Commission 2009). Arctostaphylos uva-ursi is a dominant component of montane heath in many areas from sea level on the north and far north-west coasts, through the low alpine zone, to beyond the assumed altitudinal limit of tree species in the central mountain ranges (ca $750 \mathrm{~m}$ a.s.l. (Horsfield \& Thompson 1996)). The apparent refugial property of $A$. uva-ursi in harbouring specialist ECM fungi for a range of tree species, lends it to facilitating upland woodland establishment, which should be borne in mind when selecting sites for regeneration projects.

\section{Conclusions}

The dual approach of fruit body collection coupled with below ground next-generation sequencing was successful in detecting the presence of groups of fungi that may have been missed if sampling was limited to one method alone. However, any combination of approaches will only ever detect a 'pie slice' of the community, with above ground collections missing small, hypogeous or infrequently fruiting species, and root sample sequencing exposed to a number of biases (Tedersoo et al. 2010b). As discussed earlier, careful planning is required of the spatial sampling strategy within a survey area for samples intended for next-generation sequencing, and should exceed the quantity of samples taken in this study to gain better coverage of the ECM community.

Over the seven sites studied, a typically alpine community was detected, dominated by generalist species and many Cortinarius spp., but also including alpine specialists. The overall diversity was high, including a large proportion of novel and previously unrecorded species. The ECM community associated with $A$. uva-ursi is diverse 
and unique within the UK, with the potential to provide an important environmental service by facilitating upland woodland regeneration. This study should lend weight to the consideration of dwarf alpine shrubs as important yet threatened 'habitats' for diverse ectomycorrhizal fungal communities.

Acknowledgements: The authors would like to thank Bjorn Lindahl, Karina Clemmensen, Kare Liimatainen, Tuula Niskanen, Ian Alexander, Katie Grundy, Kate Carroll, Sam Hesling, Alison Williams, Nadine Thomas, Susan Jarvis, Dave Genney, Alison Hester, Andrea Britton and Julia Fisher for their help and support throughout this project.

\section{References}

Abarenkov, K., Nilsson, R.H., Larsson, K.H., Alexander, I.J., Eberhardt, U., Erland, S., Hoiland, K., Kjoller, R., Larsson, E., Pennanen, T., Sen, R., Taylor, A.F.S., Tedersoo, L., Ursing, B.M., Vralstad, T., Liimatainen, K., Peinter, U. \& Koljalg U. 2010: The UNITE database for molecular identification of fungi - recent updates and future perspectives. - New Phytologist 186(2): 281-285.

Altschul, S.F., Gish, W., Miller, W., Myers, E.W. \& Lipman, D.J. 1990: Basic local alignment search tool. Journal of Molecular Biology 215: 403-410.

Birks, H. H., \& Mathewes, R. W. 1978: Studies in the Vegetational History of Scotland. V . Late Devensian and Early Flandrian Pollen and Macrofossil Stratigraphy at Abernethy Forest, Inverness-Shire. - New Phytologist 80: 455-484.

Britton, A. J., Beale, C. M., Towers, W. \& Hewison, R. L. 2009: Biodiversity gains and losses: Evidence for homogenisation of Scottish alpine vegetation. - Biological Conservation 142: 1728-1739.

Crous, P.W., Gams, W., Stalpers, J.A., Robert, V. \& Stegehuis, G. 2004: MycoBank: an online initiative to launch mycology into the 21 st century. - Studies in Mycology 50: 19-22.

Forestry Commission for Scotland 2009: The Scottish Government's rationale for woodland expansion. URL: http://www.forestry.gov.uk/pdf/ForestExpansion.pdf/\$FILE/ForestExpansion.pdf [8/20/2012].

FRDBI 2012: Fungal Records Database of The British Isles. Maintained by Kirk, P. \& Cooper, J.. - URL: http://www.fieldmycology.net/FRDBI/FRDBI.asp [03/01/2012].

Hollingsworth, P. \& Iason, G. 2005: Biodiversity: Taxonomy, Genetics and Ecology of Sub-Arctic Willow Scrub. - Royal Botanic Gardens Edinburgh \& Macaulay Land Use Research Institute. Unpublished report.

Horsfield, D. \& Thompson, D. 1996: Information and Advisory Note Number 26. The Uplands: guidance on terminology regarding altitudinal zonation and related terms. - Scottish Natural Heritage, Inverness.
Ihrmark, K., Bödeker, I. T., Cruz-Martinez, K., Friberg, H., Kubartova, A., Schenck, J., Strid, Y., Stenlid, J., Brandström-Durling, M., Clemmensen, K.E. \& Lindahl, B.D. 2012: New primers to amplify the fungal ITS2 region - evaluation by 454-sequencing of artificial and natural communities. - FEMS Microbiology Ecology, 82(3): 666-677.

Jumpponen, A., Trappe, J.M. \& Cazares, E. 2002: Occurrence of ectomycorrhizal fungi on the forefront of retreating Lyman Glacier (Washington, USA) in relation to time since deglaciation. - Mycorrhiza 12: 43-49.

Kernaghan, G. \& Currah, R.S. 1998: Ectomycorrhizal fungi at tree line in the Canadian Rockies. - Mycotaxon 69: 39-79.

Kernaghan, G. \& Harper, K.A. 2001: Community structure of ectomycorrhizal fungi across an alpine/subalpine ecotone. - Ecography 24: 181-188.

Knudsen, H. \& Vesterholt, J. (Eds.) 2012: Funga Nordica, 2nd Edition. - Nordsvamp, Copenhagen.

Krpata, D., Mühlmann, O., Kuhnert, R., Ladurner, H., Göbl, F. \& Peintner, U. 2007: High diversity of ectomycorrhizal fungi associated with Arctostaphylos uva-ursi in subalpine and alpine zones: Potential inoculum for afforestation. - Forest Ecology and Management 250: 167-175.

Lenoir, J., Gégout, J. C., Marquet, P., de Ruffray, P. \& Brisse, H. 2008: A significant upward shift in plant species optimum elevation during the 20th century. Science 320 (5884): 1768-71.

Milne, J. M., Ennos, R. A. \& Hollingsworth, P. M. 2006: Vegetation influence on ectomycorrhizal inoculum available to sub-arctic willow (Salix lapponum L .) planted in an upland site. - Botanical Journal of Scotland 58: 37-41.

Molina, R. \& Trappe, J.M. 1982: Lack of mycorrhizal specificity by the ericaceous hosts Arbutus menziesii and Arctostaphylos uva-ursi. - New Phytologist 90: 495-509.

Nara, K. 2006: Ectomycorrhizal networks and seedling establishment during early primary succession. - New Phytologist 169: 169-178.

Preston, C.D., Pearman, D.A. \& Dines, T.D. 2002: New Atlas of the British \& Irish Flora. - Oxford Press, Oxford, p 290.

Rinaldi, A. C., Comandini, O. \& Kuyper, T. W. 2008: Ectomycorrhizal fungal diversity: separating the wheat from the chaff. - Fungal Diversity 33: 1-45.

Tedersoo, L., May, T. W. \& Smith, M. E. 2010a: Ectomycorrhizal lifestyle in fungi: global diversity, distribution, and evolution of phylogenetic lineages. - Mycorrhiza 20: 217-63.

Tedersoo, L., Nilsson, R. H., Abarenkov, K., Jairus, T., Sadam, A., Saar, I., Bahram, M., Bechem, E., Chuyong, G. \& Kõljalg, U. 2010b: 454 Pyrosequencing and Sanger sequencing of tropical mycorrhizal fungi provide similar results but reveal substantial methodological biases. - New Phytologist 188: 291301.

Watling, R. 2002: Mycota of some British shrub-plant communities. - Feddes Repertorium 113: 161-164.

Watling, R. 2005: Fungal associates of Salix repens in northern oceanic Britain and their conservation significance. - Mycological Research 109: 1418-1424.

Zak, B. 1976: Pure culture synthesis of bearberry mycorrhizae. - Canadian Journal of Botany 54: 1297-1305. 


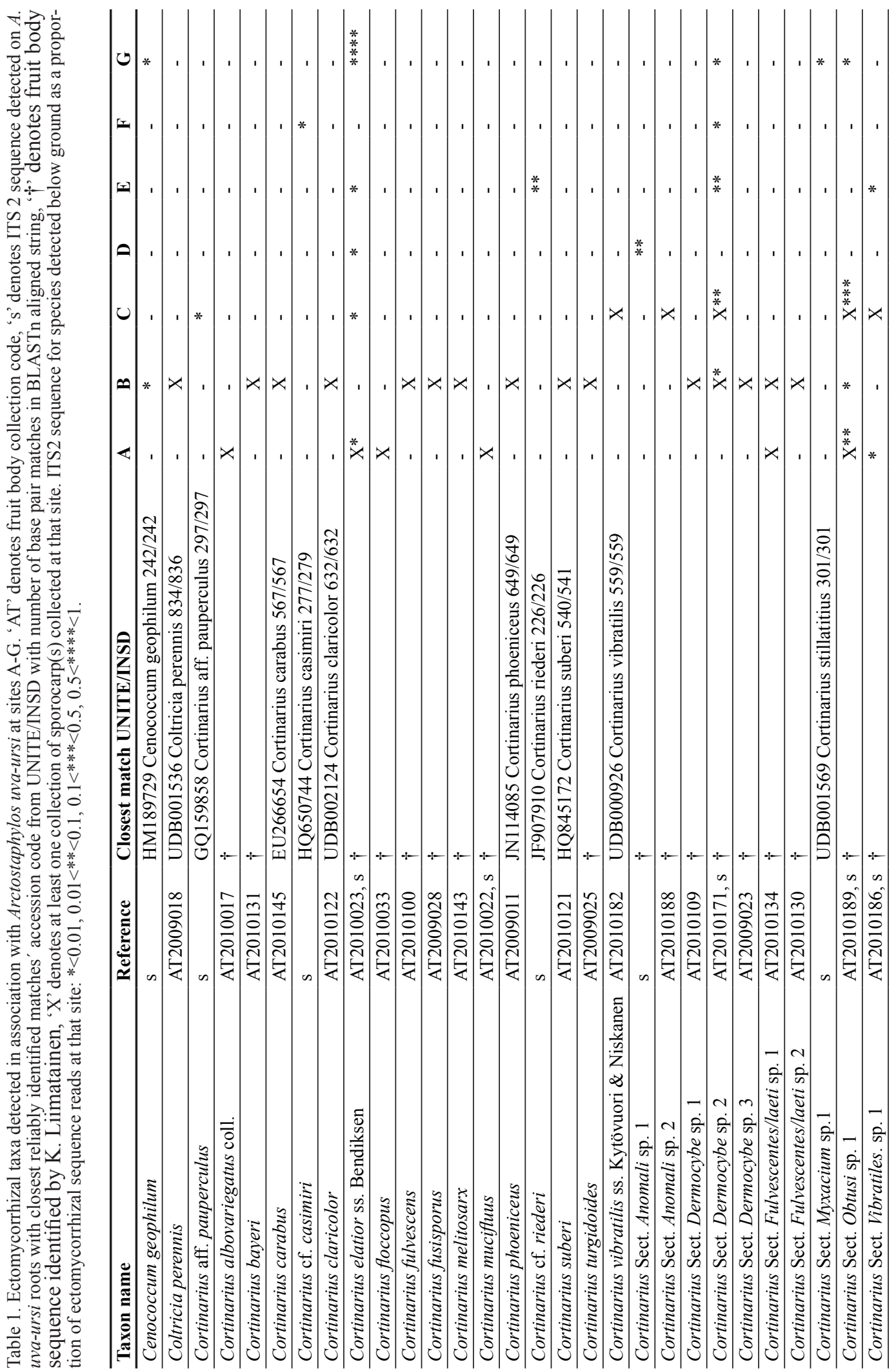




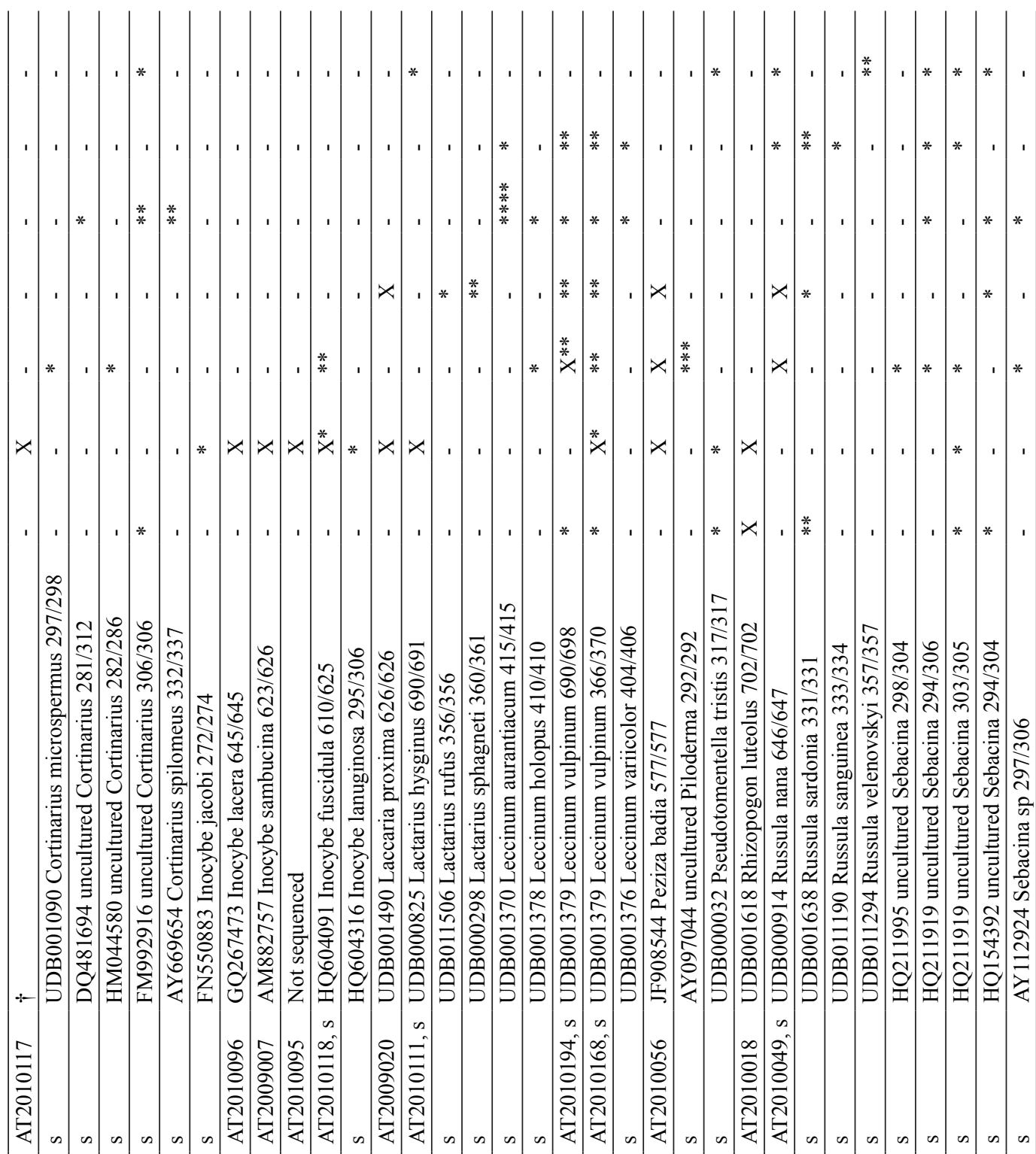

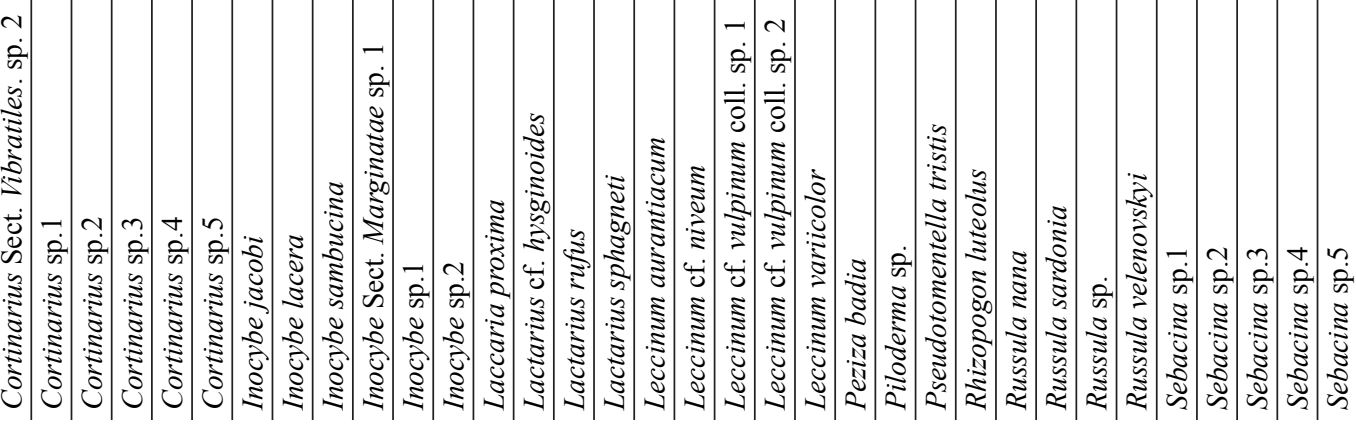




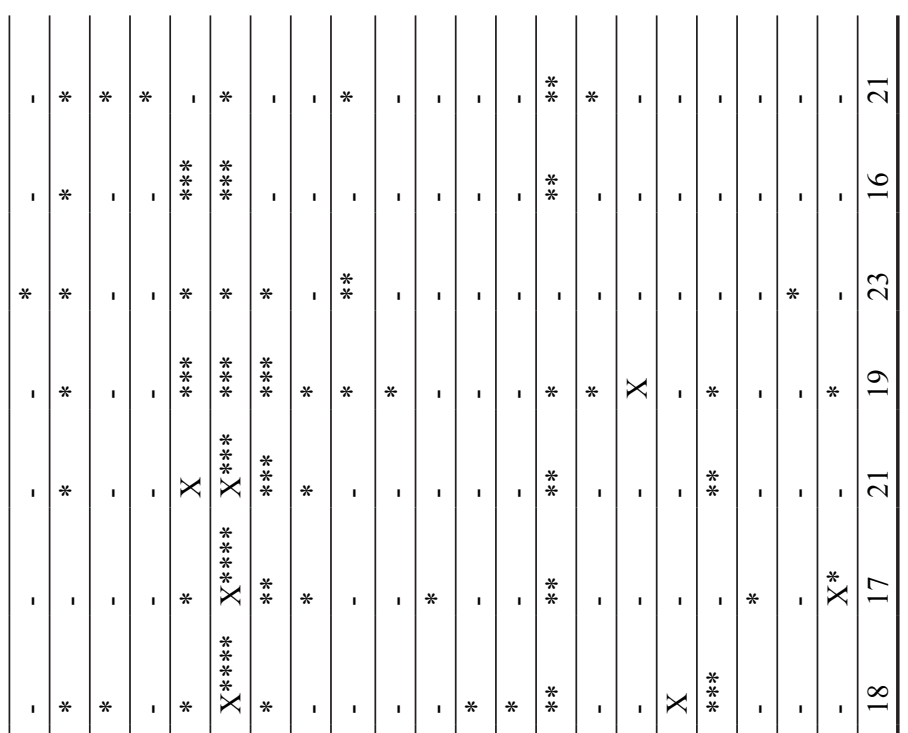

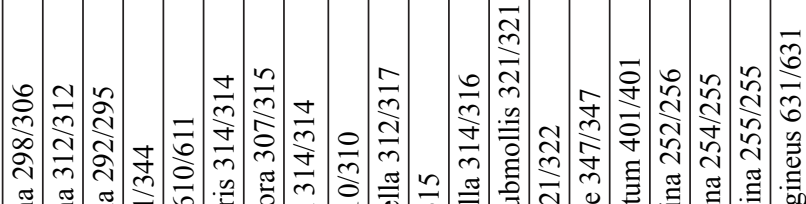

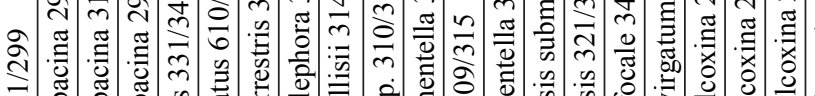

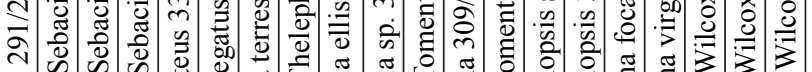

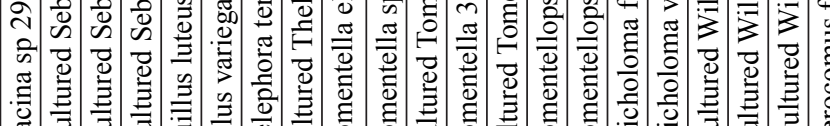

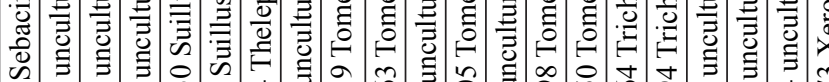

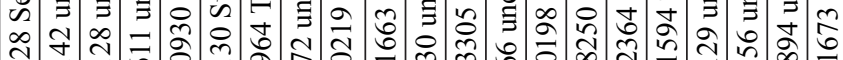

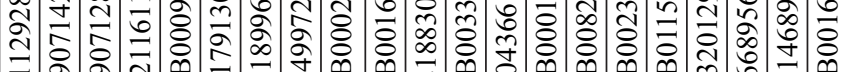

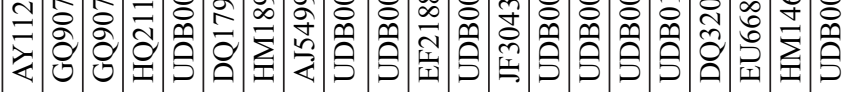

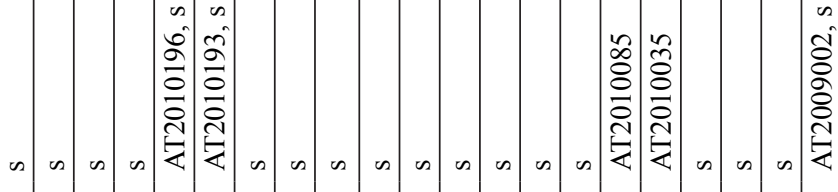

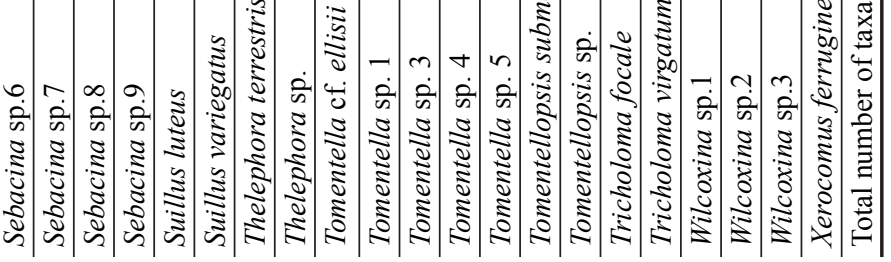




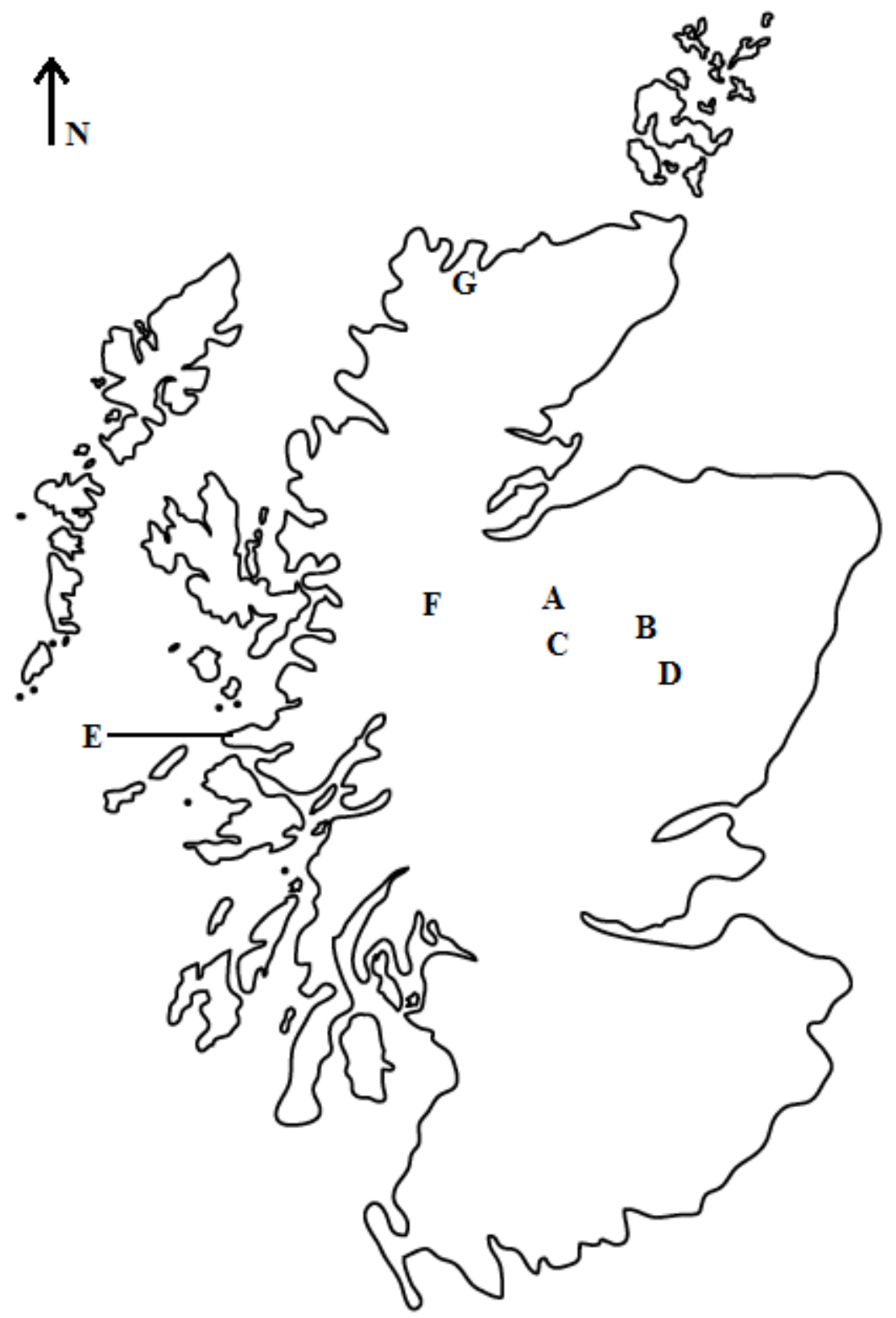

Fig. 1. Collection sites in Scotland: $\mathrm{A}=$ Carn Dearg Mor, near Aviemore, $660 \mathrm{~m}$ a.s.1.; $\mathrm{B}=$ Culardoch, near Braemar, 732 m a.s.1.; $\mathrm{C}=$ Carn Ban Beag, Glen Feshie, 764 m a.s.1.; D = Sandy Hillock - Creag Bhiòrach, Glen Muick; E = Beinn na h-Imeilte, Ardnamurchan peninsula, 165 m a.s.1.; F = Carn na Caorach, Dundreggan, 510 m a.s.1.. 